\title{
Histórico do grupo EAPS, conceito de Aparência e síntese dos resultados: dez anos de pesquisa, ensino e extensão sobre a temática Envelhecimento e Aparência
}

\author{
EAPS group history, Appearance concept, and \\ summary of the results: ten years of research, \\ teaching, and extension on the \\ theme Aging and Appearance \\ Historia del grupo EAPS, concepto de \\ Apariencia y resumen de los resultados: diez. \\ años de investigación, enseñanza y extensión \\ universitaria en el tema \\ Envejecimiento y Apariencia
}

Andrea Lopes Patrícia Yokomizo

RESUMO: A temática Envelhecimento e Aparência não tem sido discutida na Gerontologia nacional em toda a sua complexidade. $\mathrm{O}$ artigo apresenta as atividades, resultados e desafios presentes no percurso dos 10 anos do grupo de pesquisa, ensino e extensão Envelhecimento, Aparência e Significados, vinculado à EACH/USP. As contribuições do grupo foram: 1) proposição de uma temática de investigação científica, a partir da observação de demanda social específica; 2) proposta de conceito para a variável aparência; 3) oficina de extensão universitária conjunta com disciplina optativa envolvendo alunos de graduação e pós-graduação; 4) três exposições artísticas; 5) palestras diversas; 
6) um conjunto de pesquisas exploratórias, majoritariamente de caráter qualitativo, desenvolvidas por alunos de graduação e pós-graduação, algumas com financiamento; 7) um seminário de pesquisa; 8) vinculação ao diretório de grupos de pesquisa do CNPq; 9) site institucional e página no Facebook; e, por fim, 10) publicações científicas nacionais, inclusive, organização de número especial 26, de 2019, da Revista Kairós-Gerontologia sobre a temática. Os esforços visam a sensibilizar, visibilizar e fomentar o debate em torno dos aspectos socioculturais da Aparência, como modo de fortalecer e legitimar as identidades e o engajamento social, ao promover a heterogeneidade das formas de envelhecer.

Palavras-chave: Aparência; Envelhecimento; Velhice.

ABSTRACT: The Aging and Appearance theme has not been discussed in the Brazilian Gerontology in its complexity. The article presents the activities, results, and challenges present in the 10 years of the research, teaching and extension group Aging, Appearance and Meaning of the School of Arts, Sciences, and Humanities from University of São Paulo, Brazil. The group's contributions were: 1) the proposition of a theme of scientific investigation, from the observation of a specific social demand;2) the proposition of a concept for the appearance variable; 3) university extension workshop in conjunction with an elective discipline involving undergraduate and graduate students; 4) three artistic exhibitions; 5) various lectures; 6) a set of exploratory research, mostly qualitative, developed by undergraduate and graduate students, some with funding; 7) a research seminar; 8) registration in CNPq Research Groups Directory, Brazil; 9) institutional website and Facebook page; and, finally, 10) national scientific publications, including the organization of a special issue on the subject for the KairósGerontologia Journal.

Keywords: Appearance; Aging; Old age.

RESUMEN: El tema Envejecimiento y Apariencia no ha sido discutido de modo complejo en la Gerontología brasileña. De esa manera, el artículo presenta las actividades, resultados y desafíos presentes en los 10 años del grupo de investigación, enseñanza y extensión Envejecimiento, Apariencia y Significados, asociado a la Escuela de Artes, Ciencias y Humanidades de la Universidad de São Paulo, Brasil. Las

Lopes, A., \& Yokomizo, P. (2019). Histórico do grupo EAPS, conceito de Aparência e síntese dos resultados: dez anos de pesquisa, ensino e extensão sobre a temática Envelhecimento e Aparência. Revista Kairós-Gerontologia, 22(N. ․ Especial 26), Temático: "Envelhecimento e Aparência", 07-29. Print ISSN 1516-2567. ISSNe 2176-901X São Paulo (SP), Brasil: FACHS/NEPE/PEPGG/PUC-SP 
contribuciones del grupo fueron: 1) la proposición de un tema de investigación científica, a partir de la observación de una demanda social específica; 2) la proposición de un concepto de Apariencia; 3) un taller de extensión universitaria en asociación con una asignatura electiva para estudiantes de grado y posgrado; 4) tres exposiciones artísticas; 5) varias conferencias; 6) un conjunto de investigaciones exploratorias, en su mayoría cualitativas, desarrolladas por estudiantes de grado y posgrado, algunas con financiación; 7) un seminario de investigación; 8) el registro en el Directorio de Grupos de Investigación del Consejo Nacional de Desarrollo Científico y Tecnológico (CNPq), Brasil; 9) la página web institucional y el Facebook del grupo; y, finalmente, 10) publicaciones científicas nacionales, en las cuales se incluye este número especial de la Revista Kairós-Gerontología.

Palabras clave: Apariencia; Envejecimiento; Vejez.

\section{Introdução}

O artigo tem como objetivo apresentar o histórico do grupo de pesquisa, ensino e extensão Envelhecimento, Aparência e Significados (EAPS), parte da Escola de Artes, Ciências e Humanidades (EACH), da Universidade de São Paulo (USP), Brasil. Ainda, deseja-se compartilhar o conceito de Aparência proposto pelo grupo. Por fim, uma síntese envolvendo semelhanças e diferenças entre os resultados alcançados pelas pesquisas realizadas ao longo de dez anos. Atualmente, o EAPS é um dos grupos de investigação ligado à linha de pesquisa Processos Educativos no Envelhecimento, do Programa de PósGraduação em Gerontologia da EACH/USP.

Assim como a perspectiva gerontológica do envelhecimento ${ }^{1}$, ao definir o conceito de Aparência, o grupo entende essa variável como multideterminada e processual. A proposição de um conceito de Aparência emergiu da crescente insatisfação do grupo com a falta de consenso na literatura sobre esse termo e sua definição.

\footnotetext{
${ }^{1}$ Entende-se por envelhecimento humano o processo universal, heterogêneo e dinâmico que ocorre ao longo de toda a vida, fruto da combinação de determinantes biológicos, psicológicos e socioculturais (Santos, Lopes, \& Neri, 2007; Neri, 2014; Ribeiro, 2012). 
O uso indiscriminado de conceitos como moda, beleza, corpo e autoestima propunha-se a tratar, muitas vezes, da mesma perspectiva conceitual, desfechos analíticos de diferentes naturezas. Nessa direção, recentemente organizaram-se esforços para a realização de uma revisão narrativa envolvendo artigos nacionais e internacionais provenientes dos campos da Gerontologia, Moda e Antropologia. A escolha dos respectivos campos deu-se pelo especial interesse nos aspectos simbólicos da temática Envelhecimento e Aparência, foco do grupo. O resultado da revisão e proposição do termo estão publicados em Yokomizo e Lopes (2019, p. 239). Nessa direção, o EAPS investiu na união e concentração dessas contribuições e frentes fragmentadas em um único conceito mais abrangente, intencionando reunir e promover o debate em uma rumo a uma definição mais robusta e coesa, a partir da proposição de um conceito de Aparência, a saber: "um conjunto de aspectos físicos, comportamentais, atitudinais, estéticos e simbólicos construídos e externalizados pelos indivíduos ou grupos, compondo sua apresentação pessoal ou coletiva”. No mesmo artigo, o grupo ainda propõe que:

A Aparência resulta do contato pessoal e coletivo com diversos contextos e relações socioculturais, historicamente datadas, estabelecidas ou não, ao longo da vida. Através da Aparência, visa-se proteção e, especialmente, comunicar mensagens, significados, emoções, crenças, estilos e/ou tipos e compreensões de beleza. Além disso, expressa pertencimento, exercício de papéis e tarefas sociais, atendimento ou contraposição de expectativas e punições sociais reconhecidas e acordadas, muitas vezes, conforme a ocasião e o local, posto que ancoradas socioculturalmente e/ou em condições climáticas (p. 239).

Como características da construção da Aparência, o grupo defende que ela é "processual, histórica, situacional, dinâmica, interdependente e heterogênea (...) ocorre ao longo de toda a vida e em acordo com as condições e modos que os indivíduos e os grupos envelhecem nesse percurso" (Yokomizo, \& Lopes, 2019, p. 239).

Por sua natureza interdisciplinar, o EAPS conta com a interlocução de pesquisadores e colaboradores de diferentes campos de conhecimento e instituições. 
Ao longo de sua trajetória, realizou majoritariamente estudos qualitativos, de orientação etnográfica. Os paradigmas teóricos clássicos que sustentam as ações e trabalhos do grupo, explorados ao longo dos estudos presentes neste volume, são: heterogeneidade, interdependência, cultura e construção sociocultural. Em todas essas frentes, considerase a noção de engajamento social, entendido pelo grupo como envolvimento social significativo e mobilizador de crenças, atitudes e comportamentos, promovendo o bemestar ao longo do envelhecimento e da velhice, em particular. Nessa confluência teóricometodológica, pretende-se continuar avançando na compreensão simbólica da Aparência e seus desdobramentos, em face à gestão do envelhecimento individual, coletivo e institucional.

\section{A história do grupo EAPS}

A ideia de formar um grupo de pesquisa surgiu em 2007, a partir de um convite do então vice-coordenador do curso de Têxtil e Moda da EACH/USP, Prof. Dr. José Jorge Boueri Filho. Foi proposto à Prof. ${ }^{a}$ Dr. ${ }^{a}$ Andrea Lopes ministrar a disciplina Sociologia da Moda no primeiro semestre daquele ano, substituindo por seis meses a então responsável, Prof. ${ }^{a}$ Dr. ${ }^{a}$ Ana Paula Cavalcanti Simioni, em licença-maternidade.

A disciplina foi muito exitosa e os alunos demonstraram interesse em saber mais sobre o envelhecimento e refletir sobre formas de se apresentar socialmente ao longo da vida. Nesse sentido, relataram, especialmente, sobre o incômodo e a preocupação em torno das reduzidas imagens da velhice disponíveis na sociedade brasileira, debate trazido à tona pela professora Andrea. Os alunos destacavam que no campo da Moda havia também pouca amplitude com relação às diversas imagens relacionadas aos diferentes períodos do curso da vida, que não principalmente a chamada vida adulta.

Desde o fim da disciplina, sucessivas trocas informais foram sendo realizadas com os alunos interessados. Um corpus temático embrionário começou a ganhar forma e espaço nos interesses de pesquisa da professora. A docente já era muito sensível aos modos de apresentações sociais desde muito jovem, sendo um dos motivadores, inclusive, para a opção pela graduação em Ciências Sociais. Igualmente, a formação na pósgraduação em Gerontologia trouxe o estímulo para a ampliação das inquietações e curiosidade para além da formação original. 
Mais adiante, a professora Andrea Lopes foi convidada a colaborar com a pesquisa Idosos de baixa renda no Brasil. O estudo foi realizado entre junho e meados de agosto de 2009 e coordenado pelo pesquisador japonês Dr. Ryohei Konta, com financiamento do Institute of Developing Economies, Japan External Trade Organization, Japão. Participaram 100 moradores da Vila dos Idosos, São Paulo, Brasil.

Gentilmente, além de selecionar e treinar alunos monitores provenientes da Gerontologia EACH/USP, como supervisionar a coleta de dados, a Dr. ${ }^{a}$ Andrea Lopes foi também convidada a incluir, no instrumento da referida pesquisa, questões relacionadas aos seus interesses incipientes envolvendo a apresentação pessoal. A experiência de campo e a interlocução de pesquisa fortaleceram a certeza da existência de uma temática robusta de investigação, que já vinha sendo apreciada pela professora e seus alunos do curso de Moda nos regulares encontros de estudo. Assim, a Prof. ${ }^{a}$ Andrea Lopes, a partir da riqueza das pistas advindas da Vila dos Idosos, em 28 de agosto de 2009, conjuntamente com os alunos da Têxtil e Moda, em especial, Patrícia Yokomizo, uma das alunas da turma de Sociologia da Moda de 2007 e liderança atuante até hoje no grupo, fundaram o grupo EAPS, cuja temática de investigação passou a ser Envelhecimento, Aparência e Significados. A professora tem coordenado o grupo até os dias de hoje.

Inicialmente, o grupo organizou-se com alunos de diferentes turmas da graduação em Têxtil e Moda da EACH/USP. No geral, destacam-se por um maior período as participações de Caroline Miranda Bernardo, Larissa Henrici, Natália Peralta, Patrícia Mello e Thaís Fernanda Luz Yoshioka. Em abril de 2010, surgiu o convite para o grupo participar no Seminário de estudos e pesquisa de design: corpo, moda e ética - pistas para uma reflexão de valores. O evento foi organizado pelo grupo de estudos Zig-Zag: transversalidade e design de moda, da Faculdade Anhembi Morumbi, São Paulo, Brasil. O título da apresentação foi Moda e Envelhecimento, parte da mesa redonda Moda e extremos. No ano seguinte, colaborou-se com o livro resultante do evento com o capítulo Envelhecimento e velhice: pistas e reflexões para o campo da Moda (Lopes, et al., 2011). Em 03 de novembro de 2011, o EAPS participou então do lançamento do livro, sendo o referido capítulo sua primeira publicação. Agradece-se pelo convite e oportunidade oferecida pelas organizadoras do evento e da obra, Prof. ${ }^{a}$ Dr. ${ }^{a}$ Cristiane Mesquita e Prof. ${ }^{a}$ Dr. ${ }^{a}$ Kathia Castilho.

Lopes, A., \& Yokomizo, P. (2019). Histórico do grupo EAPS, conceito de Aparência e síntese dos resultados: dez anos de pesquisa, ensino e extensão sobre a temática Envelhecimento e Aparência. Revista Kairós-Gerontologia, 22(N. . Especial 26), Temático: "Envelhecimento e Aparência", 07-29. Print ISSN 1516-2567. ISSNe 2176-901X São Paulo (SP), Brasil: FACHS/NEPE/PEPGG/PUC-SP 
Ainda sobre o início das atividades do EAPS, ao final de 2009. surgiu mais um convite de pesquisa, então para colaborar com o estudo intitulado Educação permanente: benefícios da Universidade Aberta à Terceira Idade EACH/USP. O financiamento veio do Instituto Nacional de Estudos e Pesquisas Educacionais Anísio Teixeira (INEP), do Ministério da Educação. A coordenação foi realizada pela Prof. ${ }^{a}$ Dr. ${ }^{a}$ Meire Cachioni, dos cursos de Graduação e Pós-Graduação em Gerontologia da EACH/USP. A pesquisa envolveu aproximadamente 160 idosos e foi concluída em 2010. Um espaço também foi reservado para questões envolvendo a Aparência no protocolo, gerando pistas referentes à temática do Envelhecimento e Aparência no âmbito das atividades de ensino.

Avançando para 2009 até 2011, foi realizada outra parceria de pesquisa, esta mais focada nos significados de velhice e fragilidade. $\mathrm{O}$ estudo multicêntrico, que envolveu 385 idosos, foi financiado pelo Conselho Nacional de Desenvolvimento Científico e Tecnológico ( $\mathrm{CNPq}$ ) e intitulava-se Rede Fibra: perfis de fragilidade em idosos brasileiros, polo Ermelino Matarazzo, zona leste da cidade de São Paulo, Brasil.

A coordenação do estudo nessa região foi realizada pela Prof. ${ }^{a}$ Dr. ${ }^{a}$ Mônica Sanches Yassuda, igualmente dos cursos de Gerontologia da EACH/USP. A investigação da Aparência não foi diretamente incluída no protocolo. No entanto, especialmente colaborar na liderança da coleta dos dados trouxe maior amplitude da perspectiva física dessa complexa variável. A noção investigativa desses aspectos foi muito interessante para o amadurecimento da compreensão e relações que as variáveis biológicas estabeleciam com variáveis socioculturais, até então debatidas no grupo.

Ainda em 2011, a partir de suas experiências iniciais empíricas e teóricas de campo, o grupo começou a definir variáveis que poderiam vir a ser relacionadas à temática de interesse, como gênero, renda e escolaridade. Em uma reunião realizada em primeiro de abril do mesmo ano, criou-se, então, o primeiro nome do grupo, Envelhecimento, Aparência e Imagens (EAPI).

Mais adiante, em 4 de outubro e nos anos seguintes, o grupo foi convidado a ministrar a aula Envelhecimento e Aparência, na disciplina Envelhecimento $e$ Empreendedorismo, parte do curso de Graduação em Gerontologia da EACH-USP, sob o comando da Prof. ${ }^{\text {a Dr. }}{ }^{a}$ Maria Luisa Trindade Bestetti. 
Subsequentemente, em 28 de novembro de 2011, Andrea Lopes foi convidada a ser parecerista do Trabalho de Conclusão de Curso (TCC) da aluna Thaís Yoshioka, ainda membro do EAPS na época, que era orientada pela Prof. ${ }^{a}$ Dr. $^{a}$ Heloísa Buarque de Almeida, do Departamento de Antropologia da USP. O trabalho consistia em um estudo de caso sobre a trajetória da construção da aparência de uma mulher transexual jovem heterossexual, em comparação com uma travesti. O caso da transexual está apresentado neste número especial temático da revista Kairós-Gerontologia, em coautoria com a Prof. ${ }^{a}$ Andrea Lopes.

Da mesma forma, outros dois membros do grupo na época convidaram a Dr. ${ }^{a}$ Andrea Lopes para emitir pareceres de seus TCCs, Caroline Bernardo e Larissa Henrici, orientadas respectivamente pelas professoras Dr. ${ }^{a}$ Ana Lucia Pastore (departamento de Antropologia USP) e Dr. ${ }^{a}$ Isabel Italiano (curso de graduação em Têxtil e Moda USP).

A primeira aluna estudou o discurso do legislativo sobre o vestuário de vítimas de estupro no trabalho intitulado Moda como instrumento de violência: análise de processos e discursos sobre mulheres.

A segunda, por sua vez, estudou e propôs diretrizes de medidas para vestuário de idosos no trabalho denominado Um olhar da moda para os idosos: diretrizes para a criação de vestuário. A oportunidade de emitir pareceres para esses trabalhos, em parte estimulados e criados no bojo do grupo, ampliou a rede de contato e diálogo do EAPS, passando então a dialogar com professores de outras formações e interesses, inclusive para além da EACH/USP.

No ano de 2012, dispondo de mais familiaridade e domínio sobre os interesses do grupo, Andrea Lopes teve a oportunidade de orientar os primeiros TCCs envolvendo a temática aparência, atraindo então alunos da graduação em Gerontologia da EACH/USP para o EAPS. Entre eles, estão Joice Plens e Natália Polo Silva, cujos trabalhos foram imediatamente publicados (Plens, et al., 2012; Silva, Cachioni, \& Lopes, 2012). Ainda proveniente do mesmo curso, Carolina Barreta Caio é mais uma aluna que no mesmo período realizou pesquisa com o grupo, pesquisa essa sobre a aparência de imigrantes indianos de São Paulo, apresentada neste mesmo volume temático.

Outra oportunidade na ocasião foi a composição de banca e posterior coautoria da Prof. a Andrea Lopes no trabalho de TCC em Gerontologia da aluna Mariana Picolli, sob 
orientação da Prof. ${ }^{a}$ Dr. ${ }^{a}$ Bibiana Graeff (Picolli, et al., 2012) envolvendo idosos que se autointitulavam roqueiros.

Em suma, até então, apesar dos levantamentos, investimentos de campo e discussões em torno da temática Envelhecimento, Aparência e Significados, os esforços e interesses da professora Andrea Lopes ainda estavam concentrados em outros temas de pesquisa, especialmente os provenientes do seu mestrado em Gerontologia (Lopes, 2000) e de seu doutorado em Educação, área de concentração em Gerontologia (Lopes, 2006). Ela estava em seu período probatório na universidade e, concomitantemente à nova temática que surgia, investia na orientação de temas que já dominava. Assim, as primeiras pesquisas, orientações e parcerias realizadas vinham contando mais com a colaboração de estudantes da Gerontologia, visto a modesta inserção no campo da Moda e aprofundamento no conceito de Aparência feitos até então.

Inicialmente, conforme inclusive presente no nome do grupo, a noção do então EAPI sobre Aparência misturava-se com o conceito de imagens do envelhecimento. Assim, ainda em 2012, comemorou-se um ano do nome EAPI. No entanto, à medida que o grupo lentamente mapeava a literatura de interesse e se aprofundava no assunto, foi sendo percebido que as questões simbólicas eram muito pertinentes ao avanço da compreensão do grupo, especialmente devido à formação da professora e as orientações anteriores que já havia realizado. Dessa maneira, ao nome foi acrescentado o termo significado, passando a se chamar Envelhecimento, Aparência, Imagem e Significado (EAPIS).

Em 25 de maio de 2012, a professora Andrea Lopes foi convidada a fazer parte da mesa $O$ idoso no mundo do consumo, com a palestra Envelhecimento e Aparência: percepções dos moradores da Vila dos Idosos e dos alunos da UATI EACH/USP, no XVIII Congresso Brasileiro de Geriatria e Gerontologia, Rio de Janeiro. Sua tarefa foi comparar os resultados da aplicação do mesmo instrumento utilizado em ambos os locais, os quais havia pesquisado anteriormente no estudo em parceria com o Japão.

Outro desafio que foi oportunizado ao grupo em 17 de setembro de 2012 foi tratar da temática Envelhecimento e Aparência em entrevista para a repórter Letícia Gonzalez, a fim de compor uma matéria, de título Você também vai envelhecer, aceite, publicada na revista TPM, número 125, de 05 de outubro de 2012. O trabalho explorou os mitos envolvidos no processo do envelhecimento, especialmente os impactos que causavam na gestão da Aparência ao longo do envelhecimento.

Lopes, A., \& Yokomizo, P. (2019). Histórico do grupo EAPS, conceito de Aparência e síntese dos resultados: dez anos de pesquisa, ensino e extensão sobre a temática Envelhecimento e Aparência. Revista Kairós-Gerontologia, 22(N. ${ }^{\circ}$ Especial 26, Temático: "Envelhecimento e Aparência”), 07-29. Print ISSN 1516-2567. ISSNe 2176-901X São Paulo (SP), Brasil: FACHS/NEPE/PEPGG/PUC-SP 
Em seguida, em 26 de outubro do mesmo ano, os trabalhos de Joice Plens e Carolina Caio foram premiados como melhores pôsteres na V Jornada de Gerontologia da EACH/USP. Finalmente, em novembro daquele ano, Andrea Lopes, Patrícia Yokomizo, Natália Polo e Caroline Caio participaram do II Seminário de Pesquisa da mesma unidade, com a apresentação Envelhecimento e Aparência: síntese dos resultados de pesquisas em andamento do grupo EAPIS EACH/USP. O resumo foi publicado nos anais do evento.

No ano seguinte, investiu-se na criação do logo do grupo. As reuniões passaram a ser mensais, considerando que todas as integrantes haviam se formado na graduação.

Ainda em 2013, a Prof. a Andrea Lopes foi entrevistada sobre a temática em dois veículos de comunicação. Em 26 de abril no programa Globo News, da Rede Globo, sobre preconceito e aparência. Em 28 de novembro, para a revista Estar Bem, da cidade de Florianópolis, destacando a relação das imagens e significados do envelhecimento na atualidade, buscando debater mitos. Entre a realização das duas entrevistas, a Dr. ${ }^{a}$ Andrea Lopes ministrou uma aula sobre sexualidade e diferença de gênero, com destaque ao papel da variável aparência, na disciplina Envelhecimento e Sexualidade, parte do curso de Graduação em Gerontologia da EACH/USP.

Já em outubro de 2013, no IV Colóquio Internacional de Gerontologia, organizado pelo Instituto de Estudos Avançados da Faculdade de Medicina da USP Ribeirão Preto, o grupo recebeu menção honrosa pelo pôster da aluna Carolina Caio. Mais adiante, em 30 de novembro de 2013, obteve-se o primeiro lugar na categoria pôster para o TCC da aluna Joice Plens, no II Congresso Municipal sobre Envelhecimento Ativo - Cidade Amiga do Idoso, realizado pela Prefeitura de São Paulo, Grande Conselho Municipal do Idoso e Hospital Premier. Não apenas uma demanda advinda dos idosos era identificada, como também um interesse e legitimação dos pesquisadores e profissionais fazia-se presente à medida que o grupo compartilhava suas reflexões e frutos dos investimentos.

Ao longo de todo esse percurso, as diversas e diferentes atividades exercidas pelo grupo colaboraram também para a composição de uma biblioteca especializada, atualizada a cada nova pesquisa ou atividade. Apesar de observar-se a cada ano que, no geral, a literatura científica não vinha fazendo avanços frente à temática, foi possível coletar tangencialmente produções muito interessantes e estimulantes.

Lopes, A., \& Yokomizo, P. (2019). Histórico do grupo EAPS, conceito de Aparência e síntese dos resultados: dez anos de pesquisa, ensino e extensão sobre a temática Envelhecimento e Aparência. Revista Kairós-Gerontologia, 22(N. . Especial 26), Temático: "Envelhecimento e Aparência", 07-29. Print ISSN 1516-2567. ISSNe 2176-901X São Paulo (SP), Brasil: FACHS/NEPE/PEPGG/PUC-SP 
Além disso, o fato de o grupo apostar igualmente no registro visual da temática, buscando promover o diálogo entre arte e ciência, ações envolvendo produção artística sempre foram estimuladas, mesmo quando se tratava apenas do registro das atividades de pesquisa de campo.

Nos últimos seis anos, com o amadurecimento do grupo e maior clareza sobre a importância de observar os significados do envelhecer, decidiu-se então focar na variável aparência e postergar para outro momento os estudos envolvendo imagens. A decisão amparou-se nas considerações de Patrícia Yokomizo. Também artista visual, após realizar uma disciplina sobre imagens e cultura visual, aprofundou sua compreensão sobre o termo imagem e seus correlatos, como a fotografia e o vídeo. Compartilhou com o grupo a profunda, complexa, e diversificada discussão com que tomou contato. Questionou se o grupo não deveria fazer escolhas e estabelecer um foco mais preciso sobre a variável aparência, e significados em particular, que já continha seus desafios diante da carência de debate e produção nacional. Depois de muitas reflexões e trocas, o grupo passou a chamar-se Envelhecimento, Aparência e Significado (EAPS) desde 2015. O logo criado por Patrícia foi atualizado e oficialmente assumido pelo grupo, conforme apresentado no início do presente artigo.

As frentes de atuação também foram se diversificando e ganhando forma, conteúdo e legitimação institucional. No que tange às ações de ensino formal, o grupo atualmente lidera duas disciplinas de graduação. A primeira, Aspectos socioculturais do envelhecimento, explora os conceitos antropológicos constituintes do grupo, como também os aplica em diversos cenários sociais do envelhecimento, como a aparência. Essa disciplina prepara os alunos para uma optativa proposta e conquistada pelo grupo no curso de Têxtil e Moda, denominada Envelhecimento e Aparência. A disciplina é oferecida simultaneamente para a graduação em Gerontologia, ampliando e diversificando o debate em torno da temática.

A primeira versão da disciplina optativa gerou, ao final, uma exposição na biblioteca da EACH/USP intitulada Tem velho na capa! Os alunos elaboraram oito capas de revista com idosos da UATI, retratando questões vinculadas à aparência. Uma segunda exposição desse material aconteceu no bazar de inverno do parceiro de estágio obrigatório em Gerontologia, o Núcleo de Convivência para Idosos Projeto Samuel Rangel, localizado no bairro de Pinheiros, São Paulo, Brasil. 
Os modelos idosos fizeram a abertura da exposição no local, num ato de intercâmbio institucional, convidando os presentes a visitar e conhecer a UATI EACH/USP. Também relataram a relação que estabeleciam com as próprias aparências ao longo da velhice.

No campo das ações de extensão, no primeiro semestre de 2018, o grupo elaborou e ofereceu uma oficina, versão piloto, no âmbito da UNATI EACH/USP, intitulada Envelhecimento e Aparência: com que roupa eu vou? Participaram da experiência nove idosas, que foram acompanhadas individualmente por 14 monitores voluntários, provenientes da graduação e pós-graduação em Gerontologia e da graduação em Têxtil e Moda da EACH/USP. Teve-se, ainda, o prazer de contar com duas monitoras externas à USP e com a fotógrafa Marliete Rodrigues, que registrou todos os encontros.

Dentre os monitores, Mariana de Oliveira, Renan Rodrigues e Rafaela Alves Vieira prestaram suporte à coordenação da oficina, exercida pela professora Andrea. Os primeiros eram membros do EAPS e provenientes da graduação em Gerontologia. Já a monitora Rafaela pertencia ao curso de graduação em Têxtil e Moda e havia cursado a optativa Envelhecimento e Aparência.

O objetivo da oficina foi reconstruir o curso da composição da aparência ao longo da vida das idosas participantes. Frente a esse desafio, identificar as mensagens, papéis sociais, valores, normas, expectativas, frustrações, superações, ganhos e perdas. Refletiuse sobre os desafios na construção de suas identidades, tendo como foco suas aparências. Em especial, quem são e o que desejam na atual fase de suas vidas e como elas podem usar das próprias aparências para reinventar-se e apresentar-se socialmente no futuro, de forma a promover o próprio bem-estar. Estimularam-se, portanto, as noções de autonomia, interdependência, heterogeneidade e engajamento social. Nesse sentido, estimulou-se a concepção da aparência como forma de expressar mensagens e otimizar oportunidades. Observou-se que, quando significativamente engendradas e legitimadas, as aparências não enganam!

A experiência resultou em duas participações no evento IV Congresso Internacional de Gerontologia da USP e V Congresso Latino-Americano de Universidades com Carreiras em Gerontologia, realizado no segundo semestre de 2018: um desfile com todos os participantes e uma instalação na biblioteca da EACH/USP. Esta última, continha os seguintes produtos da oficina:

Lopes, A., \& Yokomizo, P. (2019). Histórico do grupo EAPS, conceito de Aparência e síntese dos resultados: dez anos de pesquisa, ensino e extensão sobre a temática Envelhecimento e Aparência. Revista Kairós-Gerontologia, 22(N. ․ Especial 26), Temático: "Envelhecimento e Aparência", 07-29. Print ISSN 1516-2567. ISSNe 2176-901X São Paulo (SP), Brasil: FACHS/NEPE/PEPGG/PUC-SP 
a) Painéis retratando a memória da trajetória da aparência;

b) Roupas customizadas, a partir da reciclagem de peças doadas pelo próprio grupo;

c) Um recordatório fotográfico, criado pela fotógrafa Marliete Rodrigues;

d) Retratos das idosas e acrósticos, confeccionados pela monitora Maria de Fátima Rodrigues.

Ainda no mesmo congresso, foram apresentadas cinco pesquisas, sendo quatro pôsteres e uma apresentação oral dos seguintes integrantes do grupo: Silvana Bassi Ramos, Leônidas Ramos, Mariana de Oliveira, Natália Tezoto e Patrícia Yokomizo. Agradecimento especial a toda a equipe organizadora do congresso pela oportunidade!

Assim, uma outra clareza que foi adquirida ao longo dos anos é a de que o grupo EAPS tem como princípio promover a ciência por meio da arte em suas ações. Nesse esforço, confere-se o destaque e agradecimento à iniciativa da monitora da oficina, Ana Maria de Souza. Ela criou e presenteou as idosas com cadernos artesanais, cujas capas foram revestidas com tecidos escolhidos por elas. O objetivo foi estimular que as participantes continuassem, após o término da oficina, tomando notas, refletindo e se mantendo à frente da trajetória da própria aparência, buscando marcar quem são. Percebeu-se na experiência que registrar e refletir sobre a construção diária da aparência e seus significados ao longo da oficina atuou como um caminho na promoção do bemestar das idosas, tal como elas iam relatando a cada encontro. Atualmente, é possível acompanhar, nas respectivas redes sociais de algumas participantes, encontros regulares entre elas e fotos que passaram a postar com diferentes vestuários ou participação em eventos diversos. O relato da experiência também está entre os trabalhos apresentados neste número especial, fruto do TCC de Renan Rodrigues de Almeida.

Por fim, voltando às ações de educação formal, o amadurecimento alcançado com a oficina e a disciplina optativa da graduação estimularam o EAPS a organizar e propor uma nova disciplina optativa, de caráter híbrido, agora para a grade da Pós-Graduação em Gerontologia, igualmente denominada Envelhecimento e Aparência. O bom desempenho resultante da proposta-piloto em unir idosos e alunos de graduação e pósgraduação na oficina estimulou o desejo de oficializar a experiência. Assim, a proposta envolvia sobrepor as três frentes em uma única ação. Obteve-se aprovação por unanimidade nas instâncias competentes da EACH/USP em 2019. 
No que tange à pesquisa, o grupo avançou na busca por financiamento. $\mathrm{Na}$ graduação, foi contemplado com duas bolsas de iniciação científica no Programa Unificado de Bolsas (PUB) USP em 2017 e 2018. Os trabalhos de Mariana de Oliveira e Leônidas Ramos visavam a discutir a temática no âmbito dos idosos envolvidos com a oficina de teatro da UATI EACH/USP, respectivamente, mulheres e homens. Os materiais também compõem este número especial.

Na Pós-Graduação em Gerontologia, Patrícia Yokomizo obteve bolsa de mestrado da Fundação de Amparo à Pesquisa do Estado de São Paulo (FAPESP), inclusive contando com o apoio da mesma instituição para a coleta de dados na Espanha, com o recurso denominado Bolsa de Estágio de Pesquisa no Exterior (BEPE).

O estudo, de natureza etnográfica e transcultural, buscou comparar a construção da aparência e seus significados entre idosas de baixa renda e escolaridade das cidades de São Paulo e Madrid. Quatro estudos provenientes dessa oportunidade constam também no presente volume temático. Outros dois trabalhos já foram publicados, sendo um em periódico da área de Comunicação (Yokomizo, \& Lopes, 2018) e outro já citado anteriormente sobre o conceito de Aparência. Agradece-se a todas as instituições envolvidas na execução e conclusão desse trabalho e à Prof..$^{a}$ Dr. ${ }^{a}$ Paloma Díaz Soloaga, tutora da pesquisa no exterior, vinculada à Universidade Complutense de Madrid.

Outro desafio que o grupo se colocou foi a realização de uma primeira pesquisa de natureza quanti-qualitativa, realizada pelas alunas Aparecida Costa da Silva e Silvana Bassi Ramos, como TCC. À Silvana interessava saber os significados de aposentadoria para idosos aposentados e vinculados ao Sindicato Nacional dos Aposentados, Pensionistas e Idosos (SINDNAPI), sede São Paulo. Já Aparecida buscava, na mesma amostra de 200 participantes, investigar os significados da aparência. A primeira pesquisa está em fase de publicação. A segunda compõe este número especial. Dado o grande entusiasmo com a temática Envelhecimento e Aparência, Silvana optou por continuar no grupo e realizar o mestrado em Gerontologia da EACH/USP.

Ainda sobre o estudo realizado no sindicato, observou-se que a prevalência foi masculina, algo raro nos equipamentos voltados para idosos. O rastreio realizado no local trouxe inúmeros dados interessantes sobre a constituição e importância da aparência para os homens idosos.

Lopes, A., \& Yokomizo, P. (2019). Histórico do grupo EAPS, conceito de Aparência e síntese dos resultados: dez anos de pesquisa, ensino e extensão sobre a temática Envelhecimento e Aparência. Revista Kairós-Gerontologia, 22(N. ${ }^{\circ}$ Especial 26), Temático: "Envelhecimento e Aparência", 07-29. Print ISSN 1516-2567. ISSNe 2176-901X São Paulo (SP), Brasil: FACHS/NEPE/PEPGG/PUC-SP 
Assim, no mestrado, Silvana investigou o universo dos misteres eleitos anualmente no Instituto Paulista de Geriatria e Gerontologia (IPGG) José Ermírio de Moraes, localizado no bairro de São Miguel Paulista, São Paulo. Seu foco foram os idosos eleitos em 2017. A experiência ocasionou dois artigos, igualmente presentes neste número especial. Nesse contexto, aproveita-se para agradecer todo o apoio e a confiança oferecidos pelo IPGG a ambas as pesquisas de mestrado do grupo, orientadas pela professora Andrea Lopes. Atualmente, a pesquisa foi aceita para ser apresentada em formato de pôster no I Congresso internacional em comunidades envelhecidas, em Portugal.

No âmbito do TCC, teve-se também a oportunidade de investigar a temática da aparência em aplicativos de relacionamentos homossexuais, estudo realizado pela participante Paula Mello Gomes, também apresentado neste volume temático. Igualmente, o trabalho de Natália Tezoto, proveniente do curso de Têxtil e Moda, teve como foco investigar os significados dos calçados para idosas do teatro da UATI.

O EAPS continuou avançando nas parcerias institucionais e participou de evento voltado para profissionais de Instituições de Longa Permanência para Idosos (ILPIs) na Defensoria Pública do Estado de São Paulo, Núcleo Especializado dos Direitos do Idoso e da Pessoa com Deficiência. O encontro foi organizado pela Prof. ${ }^{\text {a Dr. }}$. Bibiana Graeff, da Gerontologia EACH/USP, e a defensora pública Renata Tibiriça, com o apoio dos estagiários do curso. O convite foi tratar sobre a temática da Aparência e Envelhecimento no que se refere à gestão em ILPIs. Outras duas palestras foram ministradas na São Paulo Escola de Teatro, instrumentalizando os alunos do semestre, que tinham como desafio montar peças envolvendo o tema do envelhecimento. Ainda em termos da extensão, entrevistas em programas de televisão, internet e mídia impressa foram concedidas. Parcerias com unidades do Serviço Social do Comércio (SESC) de São Paulo, São Caetano e São José do Rio Preto também foram firmadas ao ministrar palestras e realizar um workshop.

Por fim, no âmbito da pós-graduação, a coordenadora do grupo EAPS foi ainda convidada a compor bancas sobre a temática, para além da EACH/USP. Primeiramente, participou do exame de qualificação da aluna Beatriz Vital Moreira, do mestrado em Administração da Faculdade de Economia e Administração da USP. 
O estudo tratou de investigar as percepções e motivações em torno de vestuário para mulheres idosas. Já fora da USP, Andrea Lopes, enquanto representante EAPS, participou ainda de banca de defesa em Educação da aluna Camila Maria Albuquerque Aragão da Universidade Nove de Julho. A pesquisa tratou de investigar as concepções sobre o conceito de moda para os professores do curso superior de tecnologia em Design de Moda do Instituto Federal do Piauí.

Parte das atividades até aqui narradas podem ser conferidas na página do grupo no site da rede Facebook (www.facebook.com/grupoeaps), no site institucional da USP (www.each.usp.br/grupoeaps) e no Diretório de Grupos de Pesquisa do Brasil, sob a responsabilidade do Conselho Nacional de Desenvolvimento Científico e Tecnológico (CNPq).

Outras duas formas de divulgação foram a organização do primeiro seminário de pesquisa do grupo intitulado Envelhecimento, Aparência e Significados: resultados dos 10 anos de pesquisa, realizado no dia 29 de novembro de 2019, nas dependências da EACH/USP, com apoio da Liga de Gerontologia da unidade. O encontro teve como objetivo central apresentar a temática e o conceito proposto de Aparência, divulgar os principais resultados de pesquisa e apresentar o presente número especial temático 26 (volume 22) da Revista Kairós-Gerontologia, como dito até aqui, com diversos estudos do grupo. No evento, foi realizada ainda a abertura de mais uma exposição fotográfica e poética, intitulada Poesia Fotográfica: Envelhecimento, Aparência e Significado, envolvendo modelos de idosas parceiras, em homenagem a todos os apoiadores do grupo. Essas conquistas encerram as atividades dos 10 anos do EAPS.

\section{Quadros-síntese}

A proposição de uma temática de pesquisa, conceito e constituição de um grupo de investigação requerem inquietação, persistência, dedicação, sensibilidade, coragem, entusiasmo, suporte institucional, parcerias, financiamento, reflexão, trocas, legitimação e constante autoavaliação, visando à profissionalização e formalização dos investimentos.

$\mathrm{O}$ avanço depende sobremaneira de intenso e continuado trabalho coletivo. As intenções devem voltar-se à proposição de respostas para as questões e inquietações do 
grupo. Com os frutos obtidos, participar, sensibilizar e fomentar o respectivo debate segue como tarefa-mestra, visando ao crescimento da proposta.

A partir desse aprendizado, pode-se resumir os esforços do grupo EAPS nos seus 10 anos de trajetória em cinco fases, que envolveram o diálogo e ações de pesquisa, ensino e extensão (Quadro 1):

Quadro 1: Síntese das fases de desenvolvimento que compuseram a trajetória dos 10 anos do grupo EAPS EACH/USP

\begin{tabular}{|c|c|}
\hline $\begin{array}{l}\text { Aproximação e } \\
\text { sensibilização } \\
\text { (Primeira fase) }\end{array}$ & $\begin{array}{l}\text { - Aproximação do campo da Moda e apresentação das inquietações } \\
\text { iniciais; } \\
\text { - } \quad \text { Sensibilização e levantamento de interesses e impressões em torno das } \\
\text { inquietações comuns; } \\
\text { - Aproximação do debate social e científico. }\end{array}$ \\
\hline $\begin{array}{l}\text { Confirmação } \\
\text { (Segunda fase) }\end{array}$ & $\begin{array}{l}\text { - Participação em estudos robustos para confirmação das pistas iniciais; } \\
\text { - Realização de pequenos estudos exploratórios em contextos e perfis já } \\
\text { de domínio do grupo, como em locais parceiros e com mulheres idosas; } \\
\text { - Início de levantamento bibliográfico sistemático, a partir da definição } \\
\text { de termos e campos de interesse; } \\
\text { - Identificação e esboço de uma problemática social relevante. }\end{array}$ \\
\hline $\begin{array}{l}\text { Reconhecimento e } \\
\text { legitimação } \\
\text { (Terceira fase) }\end{array}$ & $\begin{array}{l}\text { - Participação em eventos especializados para divulgação dos resultados } \\
\text { iniciais; } \\
\text { - } \quad \text { Reconhecimento e legitimação da comunidade especializada, científica } \\
\text { e profissional; } \\
\text { - Interesse e parceria com comunidade leiga; } \\
\text { - Ampliação dos desenhos de pesquisa e variáveis de interesse; } \\
\text { - Obtenção de financiamento; } \\
\text { - Ampliação da rede de parceiros. }\end{array}$ \\
\hline $\begin{array}{l}\text { Proposição } \\
\text { (Quarta fase) }\end{array}$ & $\begin{array}{l}\text { - } \quad \text { Amadurecimento da temática e proposição de conceito; } \\
\text { - } \quad \text { Proposição de disciplinas e oficina de extensão; } \\
\text { - } \quad \text { Realização de comunicação científica por meio de exposições artísticas. }\end{array}$ \\
\hline $\begin{array}{l}\text { Oficialização e } \\
\text { divulgação } \\
\text { (Quinta fase) }\end{array}$ & $\begin{array}{l}\text { - Divulgação de produtos e oficialização de temática de pesquisa: } \\
\text { diretório de grupos de pesquisa do CNPq, Facebook, website, evento } \\
\text { científico e caderno temático. }\end{array}$ \\
\hline
\end{tabular}

Fonte: Andrea Lopes e Patrícia Yokomizo, 2019

A busca pela produção e composição de um corpo de conhecimento sobre a temática de interesse, mesmo que inicialmente tímido e modesto, deve liderar as ações. Novos saberes alimentam novos questionamentos que, por sua vez, envolvem mais interessados, o que movimenta a temática. 
Assim, a seguir, apresenta-se um quadro (Quadro 2) que sintetiza os resultados obtidos nas pesquisas do grupo, organizados especialmente em termos de semelhanças, que foram a maioria, no que tange à construção da Aparência e seus significados na velhice ou ao longo do envelhecimento. Salienta-se que as pesquisas se concentraram nos contextos especializados de atendimento a idosos, com exceção de uma pesquisa com imigrantes indianos e duas no contexto da identidade de gênero e orientação sexual.

Quadro 2: Síntese dos resultados de pesquisas do grupo EAPS EACH/USP nos 10 anos de trajetória, em termos de semelhanças

\begin{tabular}{|c|c|}
\hline $\begin{array}{l}\text { Motivações para o } \\
\text { cuidado da aparência }\end{array}$ & 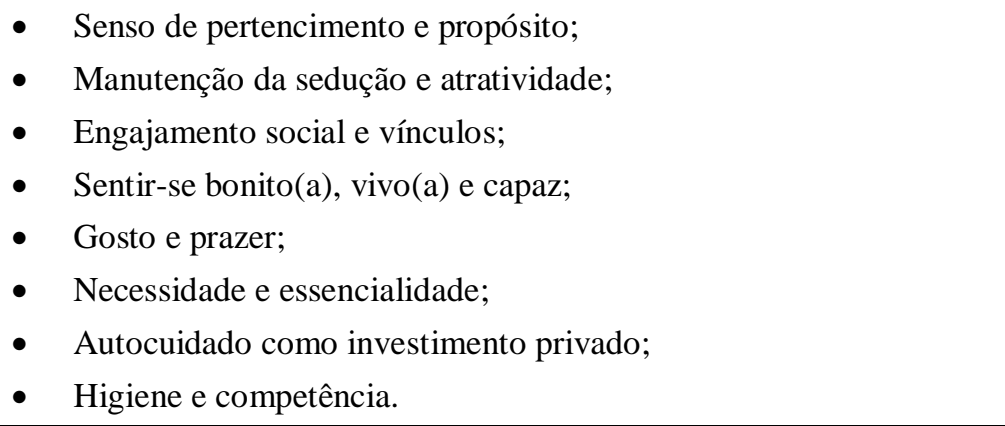 \\
\hline Crise identitária & $\begin{array}{l}\text { - } \text { Crescente insatisfação com estereótipos negativos da velhice; } \\
\text { - Tensão entre velhice e mito da juventude eterna; } \\
\text { - Senso de inadequação etária e desejo por design identitário; } \\
\text { - } \quad \text { Concepção biológica e funcional de envelhecimento e velhice. }\end{array}$ \\
\hline $\begin{array}{c}\text { Busca de avaliação e } \\
\text { aprovação }\end{array}$ & $\begin{array}{l}\text { - } \text { Pares etários; } \\
\text { - Familiares; } \\
\text { - } \text { Profissionais especializados. }\end{array}$ \\
\hline $\begin{array}{c}\text { Significados de } \\
\text { envelhecimento e } \\
\text { velhice }\end{array}$ & $\begin{array}{l}\text { - Sinônimos; } \\
\text { - Tensão entre sentimentos ancorados em noções de decadência, } \\
\text { exclusão, perdas, marginalização (marcados pela noção de velhice) } \\
\text { versus valoração da experiência de vida (marcada pela noção de } \\
\text { terceira idade). }\end{array}$ \\
\hline $\begin{array}{l}\text { Significados da } \\
\text { aparência }\end{array}$ & $\begin{array}{l}\text { - Boa aparência: zelo e limpeza, autocontrole, rede de suporte social, } \\
\text { autoestima, envolvimento social/familiar, bons modos/educação, } \\
\text { domínio dos códigos sociais, tradição, dignidade, adequação etária, } \\
\text { posse de acervo pessoal e status superior; } \\
\text { - Má aparência: abandono, mal cheiro, dependência, incapacidade, } \\
\text { ausência de acervo pessoal, desleixo, isolamento social, ausência } \\
\text { de vínculo, falta de educação, mau gosto, parecer velho e } \\
\text { inadequação etária; } \\
\text { - Significados gerais: cartão de visita e identidade; dinâmica e } \\
\text { processual. }\end{array}$ \\
\hline
\end{tabular}

Lopes, A., \& Yokomizo, P. (2019). Histórico do grupo EAPS, conceito de Aparência e síntese dos resultados: dez anos de pesquisa, ensino e extensão sobre a temática Envelhecimento e Aparência. Revista Kairós-Gerontologia, 22(N. ${ }^{\circ}$ Especial 26), Temático: "Envelhecimento e Aparência", 07-29. Print ISSN 1516-2567. ISSNe 2176-901X São Paulo (SP), Brasil: FACHS/NEPE/PEPGG/PUC-SP 


\begin{tabular}{|c|c|}
\hline Funções da aparência & $\begin{array}{l}\text { - } \quad \text { Expressão de autonomia e funcionalidade; } \\
\text { - } \quad \text { Conforto e segurança; } \\
\text { - } \quad \text { Vestir-se e comportar-se; } \\
\text { - } \quad \text { Diferenciação versus pertencimento; } \\
\text { - } \quad \text { Oportunidade de ressignificação. }\end{array}$ \\
\hline $\begin{array}{l}\text { Investimentos na } \\
\text { aparência }\end{array}$ & $\begin{array}{l}\text { - Roupas e acessórios; } \\
\text { - Cosméticos; } \\
\text { - Tratamentos de beleza; } \\
\text { - Atualização e consumo de conteúdos midiáticos sobre aparência; } \\
\text { - Desejo de consumo e ausência de ofertas interessantes; } \\
\text { - Manutenção de acervo pessoal; } \\
\text { - Financiamento próprio e familiar; } \\
\text { - Trocas e doações; } \\
\text { - Autogratificação; } \\
\text { - Estímulo para autogestão da vida. }\end{array}$ \\
\hline $\begin{array}{l}\text { Ocasiões de } \\
\text { performance da } \\
\text { aparência }\end{array}$ & $\begin{array}{l}\text { - Espaços especializados para idosos; } \\
\text { - Eventos familiares; } \\
\text { - Falta de convites, para além do espaço familiar e instituições } \\
\text { especializadas. }\end{array}$ \\
\hline $\begin{array}{l}\text { Inspirações para } \\
\text { composição da } \\
\text { aparência }\end{array}$ & $\begin{array}{l}\text { - Tipo de ocasião; } \\
\text { - Profissionais especializados; } \\
\text { - Família; } \\
\text { - Amigos e pares etários. }\end{array}$ \\
\hline Modos de vestir & $\begin{array}{ll}\text { - } & \text { Discrição } \\
\text { - } & \text { Simplicidade } \\
\text { - } & \text { Neutralidade } \\
\text { - } & \text { Conforto } \\
\text { - } & \text { Naturalidade } \\
\text { - } & \text { Qualidade. }\end{array}$ \\
\hline
\end{tabular}

Fonte: Andrea Lopes e Patrícia Yokomizo (2019)

A identificação de um maior número de semelhanças do que diferenças entre os estudos pode delatar a força que o modelo dicotômico de velhice, decadente versus ativa, ainda detém nas mentalidades, crenças, atitudes e convívio social. No que tange às diferenças, observaram-se as seguintes pistas (Quadro 3): 
Quadro 3: Síntese dos resultados de pesquisas do grupo EAPS EACH/USP nos 10 anos de trajetória, em termos de diferenças

\begin{tabular}{|c|}
$\begin{array}{c}\text { Maior segmentação das formas de apresentação e sedução por meio da aparência } \\
\text { entre homossexuais do que heterossexuais. }\end{array}$ \\
\hline $\begin{array}{c}\text { Maior militância etária e de gênero entre os homens de menor renda e escolaridade, } \\
\text { do que entre aqueles pertencentes a extratos superiores. }\end{array}$ \\
\hline Maior competividade na construção da aparência entre mulheres do que homens. \\
Maior recebimento de suporte por parte dos homens de suas esposas na gestão \\
dacia do que o oposto. \\
\hline Diferentes níveis de investimentos e interesses no exercício da competência em buscar, interpretar e \\
dominar códigos de apresentação pessoal.
\end{tabular}

Fonte: Andrea Lopes e Patrícia Yokomizo (2019)

De modo geral, as diferenças e semelhanças, mesmo não sendo este o foco dos estudos a ser retratado, trazem inúmeras informações de universos, tensões e relações que pouco vem se discutindo por meio da abordagem simbólica da aparência ao longo do processo de envelhecimento e velhice. Percebeu-se que as variáveis que trouxeram mais pistas nessa direção, quando combinadas, foram: renda, escolaridade, estado civil, identidade de gênero e sexual, geração, tipo de engajamento e vida laboral.

Espera-se que os resultados aqui elencados sumariamente sirvam de pistas e inspirações para novos estudos e aprofundamento do debate sobre Envelhecimento e Aparência, no âmbito dos significados que engendram. Mais do que negar ou superestimar a velhice, percebeu-se que os participantes querem ser reconhecidos por suas especificidades, desejos e necessidades, que são dinâmicas e processuais, ainda que em um contexto de busca por visibilidade, aceitação, reconhecimento, legitimação e pertencimento a códigos que são coletivamente orquestrados. 


\section{Agradecimentos}

Mediante inúmeras oportunidades acadêmico-científicas e comunitárias são inúmeras as pessoas a continuar agradecendo. Correndo o risco do esquecimento, o EAPS agradece por esses 10 anos a todos os servidores docentes e técnico-administrativos da EACH/USP e de universidades e instituições parceiras, pela atenção, apoio, interesse e aprendizado. Em especial, aos docentes dos Programas de Gerontologia e Têxtil e Moda da instituição, nas pessoas das professoras Dr. ${ }^{a}$ Marisa Accioly Rodrigues da Costa Domingues, Dr. ${ }^{a}$ Maria Luisa Trindade Bestetti e Dr. ${ }^{a}$ Isabel Cristina Italiano, pelo incentivo e participação em diversas bancas, como também envio de materiais estimulantes ao longo de todos esses anos. Igualmente, aos coordenadores dos respectivos cursos da graduação, como da pós-graduação em Gerontologia, Profas. Dras. Rosa Yuka Sato Chubaci e Ruth Caldeira de Melo e Prof. Dr. Maurício de Campos Araújo, pelo apoio institucional na integração dos dois campos nas disciplinas optativas.

Deseja-se ainda agradecer sobremaneira toda a equipe da biblioteca da EACH/USP e do Projeto Samuel Rangel pelo espaço, apoio e entusiasmo em todos esses anos! Destaca-se que as equipes da biblioteca - lideradas por Rosa Tereza Tiermo Plaza e Analúcia Recine - e do Samuel Rangel, coordenado por Edima Donnabella, sempre estiveram prontamente disponíveis, apoiando cada proposta de parceria ou iniciativa. Com igual importância, agradece-se ao Prof. Rogério Pimenta e a todos os idosos da oficina de teatro da UNATI EACH/USP que ele lidera, pela parceria, apoio e carinho. Ainda, agradecemos à coordenação da UNATI EACH/USP pela confiança e apoio na pessoa da Prof. ${ }^{a}$ Dr. ${ }^{a}$ Meire Cachioni.

O EAPS é certamente fruto dos esforços dos aqui nomeados e de inúmeras outras pessoas e instituições, sem contar o suporte advindo das famílias e amigos dos integrantes!

Para concluir, confere-se um agradecimento muito especial aos jovens e velhos estudantes da EACH/USP que integraram o grupo e tanto apoiaram, entusiasmaram e acreditaram nas propostas do EAPS ao longo desses 10 anos de história! Da mesma forma, pouco se teria avançado se o contexto do projeto pedagógico da EACH/USP não fosse calcado no estímulo à interdisciplinaridade e à proposição de pedagogias ativas. Espera-se que o nascimento de uma temática tão relevante de pesquisa, ensino e extensão se fortaleça a cada novo investimento. 


\section{Referências}

Lopes, A. (2000). Os desafios da Gerontologia no Brasil. Campinas, SP: Alínea.

Lopes, A. (2006). Trabalho voluntário e envelhecimento: um estudo comparativo entre idosos americanos e brasileiros. Campinas, SP: Unicamp, Universidade Estadual de Campinas: Doutorado em Educação.

Lopes, A., Yokomizo, P., Bernardo, C. M., Silva, L. H., Mello, P., \& Yoshioka, T. F. L. (2011). Envelhecimento e velhice: pistas e reflexões para o campo da moda. In: Cristiane Mesquita, \& Kathia Castilho. (Orgs.). Corpo, moda e ética: pistas para uma reflexão de valores, 45-54. São Paulo, SP: Estação das Letras e Cores.

Neri, A. L. (2014). Palavras-chave em Gerontologia (4 $4^{\mathrm{a}}$ ed., v. Coleção Velhice e Sociedade). Campinas, SP: Alínea.

Picolli, M., Lopes, A., Araújo, J. R. C., \& Graeff, B. (2012). Idosos "roqueiros" e a juventude eterna: pistas para reflexão. Revista Kairós-Gerontologia, 15(N. ${ }^{\circ}$ Especial 13, Temático "Vulnerabilidade/Envelhecimento e Velhice: Aspectos Biopsicossociais"), 291-312. Recuperado em 01 dezembro, 2018, de: https://revistas.pucsp.br/index.php/kairos/article/view/17308.

Plens, J., Accioly, M., Batistoni, S., \& Lopes, A. (2012). Envelhecimento, engajamento e aparência: percepções de idosas participantes de um núcleo de convivência de idosos. Revista Kairós-Gerontologia, 15(N. ${ }^{\circ}$ Especial 13, Temático "Vulnerabilidade/Envelhecimento e Velhice: Aspectos Biopsicossociais"), 269-289. Recuperado em 01 dezembro, 2018, de: https://revistas.pucsp.br/kairos/article/view/17307/30497.

Ribeiro, O. (2012). O envelhecimento "ativo" e os constrangimentos da sua definição. Sociologia, Revista da Faculdade de Letras da Universidade do Porto, 2(N. ${ }^{\circ}$ temático: "Envelhecimento demográfico"), 33-52. Recuperado em 01 novembro, 2018, de: https://www.redalyc.org/pdf/4265/426539987004.pdf.

Santos, G. A., Lopes, A., \& Neri, A. L. (2007). Escolaridade, raça e etnia: elementos de exclusão social de idosos. In: Neri, A. L. (Org.). Idosos no Brasil: vivências, desafios e expectativas na terceira idade. São Paulo, SP: Editora Fundação Perseu Abramo, Edições SESC SP, 65-80.

Silva, N. P., Cachioni, M., \& Lopes, A. (2012). Velhice, imagem e aparência: a experiência de idosos da UNATI EACH/USP. Revista Kairós-Gerontologia, 15(N. ${ }^{\circ}$ Especial 14, Temático "Universidade Aberta à Terceira Idade e Velhice), 235-257. Recuperado em 01 novembro, 2018, de: https://revistas.pucsp.br/kairos/article/view/15251/11377.

Yokomizo, P., \& Lopes, A. (2018). As mídias como agentes de educação informal no envelhecimento: pistas para investigação. Revista Mídia e Cotidiano, 12(3), 293-311. Recuperado em $01 \quad$ novembro, 2018, de: http://periodicos.uff.br/midiaecotidiano/article/view/13342/16056.

Lopes, A., \& Yokomizo, P. (2019). Histórico do grupo EAPS, conceito de Aparência e síntese dos resultados: dez anos de pesquisa, ensino e extensão sobre a temática Envelhecimento e Aparência. Revista Kairós-Gerontologia, 22(N. ${ }^{\circ}$ Especial 26), Temático: "Envelhecimento e Aparência", 07-29. Print ISSN 1516-2567. ISSNe 2176-901X. São Paulo (SP), Brasil: FACHS/NEPE/PEPGG/PUC-SP 
Yokomizo, P., \& Lopes, A. (2019). Aparência: uma revisão bibliográfica e proposta conceitual. Revista Dobras, 12(26), 227-244. Recuperado em 01 novembro, 2018, de: https://dobras.emnuvens.com.br/dobras/article/view/922.

Andrea Lopes - Antropóloga, docente da Pós-Graduação em Gerontologia e das Graduações em Gerontologia e Têxtil e Moda. Fundadora e coordenadora do grupo de pesquisa, ensino e extensão Envelhecimento, Aparência e Significado (EAPS), todos da Escola de Artes, Ciências e Humanidades (EACH) da Universidade de São Paulo (USP), Brasil.

E-mail: andrealopes@usp.br

Patrícia Yokomizo - Graduação em Têxtil e Moda, mestre em Gerontologia, fundadora e membro do EAPS, todos da EACH/USP, Brasil.

E-mail:pati@usp.br 